\title{
LncRNA as a diagnostic and prognostic biomarker in bladder cancer: a systematic review and meta-analysis
}

This article was published in the following Dove Press journal: OncoTargets and Therapy

\author{
Jing Quan ${ }^{1,2}$ \\ Xiang Pan ${ }^{1,2}$ \\ Liwen Zhao ${ }^{1,2}$ \\ Zuwei $\mathrm{Li}^{\prime}$ \\ Kangfu Dai \\ Fangli Yan ${ }^{2}$ \\ Suyue Liu $^{2}$ \\ Hongfei $\mathrm{Ma}^{2}$ \\ Yongqing Lai ${ }^{1,2}$ \\ 'Department of Urology, Peking \\ University Shenzhen Hospital, \\ Shenzhen, Guangdong 518036, China; \\ ${ }^{2}$ Graduate school, Anhui Medical \\ University, Hefei, Anhui 230032, China
}

Correspondence: Yongqing Lai Department of Urology, Peking University Shenzhen Hospital, I 20 Lianhua Road, Shenzhen, Guangdong 518036, China Email yqlord@163.com
Background: Bladder cancer is one of the most common urinary malignancies, and has a high recurrence rate and poor outcomes. In order to identify novel diagnostic and prognostic biomarkers for bladder cancer, we conducted a meta-analysis to analyze the association between long non-coding RNA (lncRNA) expression and survival in bladder cancer.

Materials and methods: We searched literature from databases using our inclusion and exclusion criteria. STATA 14.0 software was used to analyze the data from collected studies and to construct the forest plots. A different effect size was selected for each meta-analysis.

Results: After selection, 30 articles were found to be eligible. The present meta-analysis contains data from 13 articles about clinicopathological characteristics, six articles about diagnosis, and 16 articles about prognosis. In the present study, we found that many lncRNAs could function as potential diagnostic and prognostic markers in bladder cancer. Among these findings, UCA1 was expected to be a diagnostic biomarker for bladder cancer, while the aberrant expression of HOTAIR and GAS5 was associated with poor disease-free survival/recurrence-free survival/ disease-specific survival.

Conclusion: Overall, the present study is the first meta-analysis to assess the association between expression of IncRNAs and clinical value in patients with bladder cancer. LncRNAs hold promise as novel diagnostic and prognostic markers in bladder cancer.

Keywords: IncRNA, bladder cancer, clinicopathological characteristics, prognosis

\section{Introduction}

Bladder cancer is one of the most common urinary malignancies accounting for $90 \%-95 \%$ of all urothelial carcinomas. The age-standardized incidence rate (per 100,000 person-years) of bladder cancer is 9.0 for men and 2.2 for women worldwide. ${ }^{1}$ In the European Union, the age-standardized incidence rate is 12.8 for men and 4.0 for women. ${ }^{1}$ Finally, the age-standardized incidence rate is 19.1 for men and 2.8 for women in Japan. ${ }^{2}$ Moreover, there was an estimated 76,960 new cases $(58,950$ men and 18,010 women) of urinary bladder cancer diagnosed in the USA in $2016 .{ }^{3}$ Despite advancement in treatment for bladder cancer in the past years, the 5-year overall survival (OS) rate remains unsatisfying, especially for metastatic bladder cancer. ${ }^{1-3}$ As we know, the prognosis of bladder cancer is associated with the tumor stage, so seeking a novel diagnostic and prognostic biomarker is important for effective treatment.

Long non-coding RNAs (lncRNAs) belong to the ncRNA family, which are defined as transcripts longer than 200 nucleotides. ${ }^{4}$ With the rapid development of cancer genomics, more and more lncRNAs have demonstrated important action in the initiation and development of tumors. ${ }^{5}$ For example, HOTAIR was shown to be highly expressed 
in non-small-cell lung cancer (NSCLC), affecting tumorigenesis and metastasis of NSCLC. ${ }^{6}$ Moreover, Srivastava et al found that IncRNCA UCA1 was overexpressed in bladder cancer and that elevated expression of UCA1 was positively associated with tumor grade. A further study suggested that UCA1 can be used as a noninvasive diagnostic biomarker in transitional cell carcinoma. ${ }^{7}$ It is worth mentioning that the US Food and drug administration (FDA) has approved the prostate cancer antigen 3 (PCA3) clinical test to replace the previous prostate specific antigen (PSA) analysis. Because of the high specificity (SPE) and sensitivity (SEN) of PCA3 detection, it can be used to diagnose prostate cancer quickly and easily, which is superior to PSA. ${ }^{8,9}$

However, most of the previously mentioned studies lack a sufficiently large sample size and have artificial errors, so it is recommended that they be combined and the potential clinical value of lncRNAs in bladder cancer be systematically analyzed. To date, no meta-analysis of the association between IncRNAs and bladder cancer has been published. Therefore, the present study is the first to systematically detail the relationship between lncRNAs and bladder cancer. In this study, results were organized to address three main topics: clinicopathological features, diagnosis, and prognosis. The essential lncRNAs described in this analysis may prove to be novel diagnostic and prognostic biomarkers for bladder cancer.

\section{Materials and methods Literature search}

Two of the authors (Jing Quan and Xiang Pan) each searched several databases, including PubMed, Embase, and the Cochrane Library, for studies of IncRNAs and bladder cancer. The publication dates used in the literature search was from database inception to November 1, 2017. The following search terms were used to retrieve articles and abstracts: (lncRNA OR lincRNA OR long non-coding RNA OR long untranslated RNA OR long non-protein-coding RNA OR long intergenic non-protein coding RNA) and (bladder cancer OR bladder neoplasm OR bladder tumor OR bladder urothelial carcinoma OR urinary bladder neoplasm OR cancer of the bladder OR malignant tumor of urinary bladder).

\section{Inclusion and exclusion criteria}

All included studies met the following inclusion criteria: 1) study patients were diagnosed with bladder cancer by histopathology; 2) study investigated the association between the expression of IncRNAs and clinicopathological features; 3) the expression level of lncRNAs was divided into two levels: high or low; 4) sufficient data, including SEN, SPE, survival outcome, or HR,
95\% CI and Kaplan-Meier curve, or if unavailable, related data obtained by contacting the corresponding authors.

Exclusion criteria were: 1) duplicate study; 2) study data incomplete or not of high quality; 3) study was a meeting report, review, meta-analysis article, animal or cell study; and 4) study included data from The cancer genome atlas (TCGA) database.

\section{Extracted data and assessment of quality}

Two independent authors (Jing Quan and Xiang Pan) collected the following information from the literature for each publication: author and publication year, region, type of $\operatorname{lncRNA}$, expression, detected sample, test method, cut-off value, validation sample, number of cases, survival analysis, HR, and follow-up times. We assessed the quality of all the included diagnostic studies according to the Quality Assessment of Diagnostic Accuracy Studies-2 (QUADAS-2) criteria $^{10}$ and used the Newcastle-Ottawa Scale $(\mathrm{NOS})^{11}$ to assess the quality of the selected prognostic studies (score $>5$ was regarded as high quality).

\section{Statistical analysis}

Heterogeneity among studies was assessed by Cochran's $Q$-test and Higgin's $I^{2}$ statistic. $P<0.05$ or $I^{2}>50 \%$ indicated that heterogeneity was considered statistically significant. To evaluate the relationship between lncRNA expression and survival outcomes, a fixed-effects or random-effects model was used. A random-effects model (Mantel-Haenszel test) was applied in the absence of between-study heterogeneity ( $P \leq 0.05$ or $I^{2} \geq 50 \%$ ). Otherwise, a fixed-effects model was used. ${ }^{12}$ A different effect size was selected for each metaanalysis. 1) For the meta-analysis of clinicopathological features, the OR and associated 95\% CI was used. 2) Metaanalysis of diagnosis, SEN, SPE, and area under curve (AUC) was used. 3) The HR and associated 95\% CI for each study was used to estimate the survival outcomes associated with the expression of IncRNA. HR $>1$ was regarded as a worse survival for the group with elevated lncRNA expression. STATA 14.0 software (StataCorp LP, College Station, TX, USA) was used to analyze study data and construct the forest plot. $P<0.05$ was considered to be statistically significant.

\section{Result Study features}

A total of 394 publication titles were downloaded from PubMed, Embase, and the Cochrane Library after using the relevant search terms. A total of $\mathbf{3 7 4}$ publication titles were downloaded from PubMed, Embase, and the Cochrane Library after using the relevant search terms. A total of $\mathbf{1 9 0}$ 
publications were excluded due to repetition; a further 129 publications were excluded based on their titles and abstracts. The remaining 55 full-text publications were retrieved. Subsequently, 25 of these studies were excluded for various reasons: including 13 without essential data, four focusing on other tumors, three with TCGA data, three with descriptions of genetic variation, and two more duplicate reports. In the end, 30 articles were eligible for this study. The present metaanalysis on lncRNA and bladder cancer analyzed 13 articles about clinicopathological characteristics, ${ }^{13-25}$ six articles about diagnosis, ${ }^{7,26-30}$ and 16 articles about prognosis. ${ }^{13,15,23,28,31-42}$ The study selection process is shown in Figure 1.

\section{Clinicopathological characteristics}

After screening, 13 publications on clinicopathological characteristics were included. Except BANCR, most of the lncRNAs were overexpressed, including SPRY4-IT1, UBC1, ASAP1IT1, PANDAR, ZEB1-AS1, ROR, MIT31HG, SUMO1P3, ABHD11-AS1, AATBC, CCAT2, and HIF1A-AS2. All were detected by RT-qPCR. The results (Table 1) demonstrated that IncRNA expression was not significantly associated with gender, age, and tumor size. Nine studies reported that lncRNAs were associated with histological grade, while almost all studies demonstrated that the abnormal expression of IncRNAs was related to tumor stage, except UBC1. Additionally, nearly all studies showed that lncRNAs were significantly correlated with tumor stage. Finally, there was a significant correlation observed between the up-regulation of IncRNA SPRY4-IT1, UBC1, and ROR and lymph node metastasis.

\section{Diagnosis}

The QUADAS-2 scores of all included literature are presented in Table 2. The majority of the eight studies in the current meta-analysis met most items in QUADAS-2, suggesting that the overall quality of included studies was moderate to high. The present meta-analysis contained 725 patients with bladder cancer and 510 healthy controls. The meta-analysis result showed that significant heterogeneity between these studies was observed among SEN and SPE data $\left(I^{2}=95.42 \%\right.$ and $I^{2}=93.33 \%$, respectively). Therefore, the random effects model was used to calculate the pooled diagnostic parameters of the included studies. The pooled estimates of all included lncRNAs for the diagnosis of bladder cancer were as follows: SEN, 0.73 (95\% CI, 0.58-0.84);

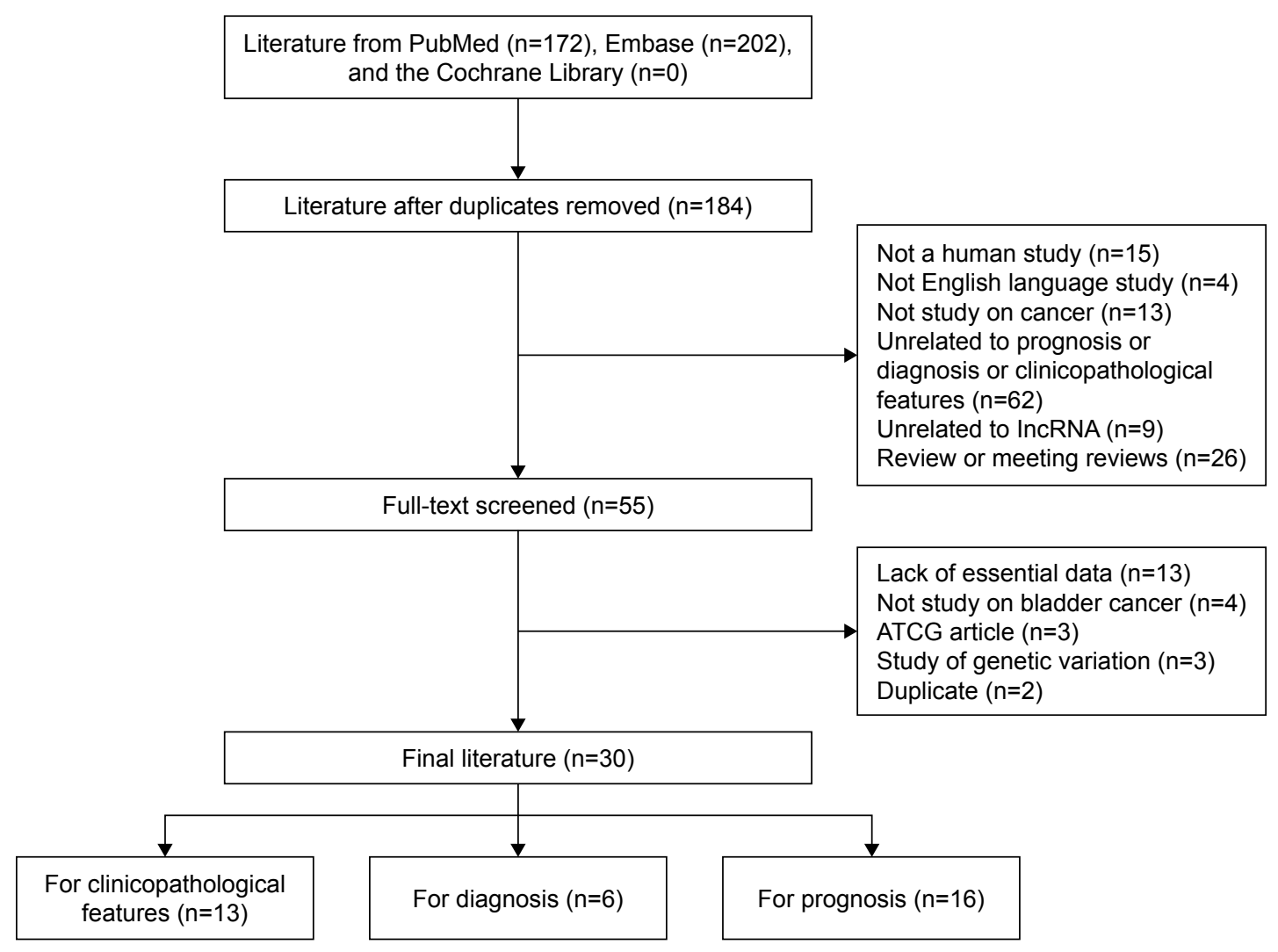

Figure I The study selection process. Abbreviation: IncRNA, long non-coding RNA. 
Table I The association between IncRNAs and clinicopathological features

\begin{tabular}{|c|c|c|c|c|c|c|c|c|c|c|c|}
\hline Study & Region & LncRNA & $\begin{array}{l}\text { Simple } \\
\text { size }(n)\end{array}$ & Age & Gender & $\begin{array}{l}\text { Tumor } \\
\text { size }(\mathrm{cm})\end{array}$ & $\begin{array}{l}\text { Histological } \\
\text { grade (I-IV) }\end{array}$ & $\begin{array}{l}\text { Tumor } \\
\text { stage } \\
\text { (TI-T4) }\end{array}$ & $\begin{array}{l}\text { Lymph } \\
\text { node } \\
\text { metastasis }\end{array}$ & $\begin{array}{l}\text { Detection } \\
\text { method }\end{array}$ & Expression \\
\hline $\begin{array}{l}\text { He et al, } \\
2013^{13}\end{array}$ & China & $\mathrm{UBCI}$ & 102 & 0.961 & 0.655 & NA & NA & 0.422 & 0.021 & RT-qPCR & Up-regulation \\
\hline $\begin{array}{l}\text { Zhao et al, } \\
2015^{14}\end{array}$ & China & AATBC & 90 & 0.863 & 0.899 & NA & 0.010 & 0.015 & 0.315 & RT-qPCR & Up-regulation \\
\hline $\begin{array}{l}\text { Zhao et al, } \\
2015^{15}\end{array}$ & China & SPRY4-ITI & 68 & 0.790 & 0.707 & 0.874 & 0.000 & 0.017 & 0.000 & RT-qPCR & Up-regulation \\
\hline $\begin{array}{l}\text { Zhan et al, } \\
2016^{16}\end{array}$ & China & PANDAR & 55 & 0.745 & 0.953 & 0.061 & 0.010 & 0.027 & 0.607 & RT-qPCR & Up-regulation \\
\hline $\begin{array}{l}\text { He et al, } \\
2016^{17}\end{array}$ & China & MIT3IHG & 55 & 0.607 & 0.415 & 0.109 & 0.415 & 0.010 & 0.114 & RT-qPCR & Up-regulation \\
\hline $\begin{array}{l}\text { Zhan et al, } \\
2016^{18}\end{array}$ & China & SUMOIP3 & 55 & 0.580 & 0.528 & 0.114 & 0.005 & 0.037 & 0.618 & RT-qPCR & Up-regulation \\
\hline $\begin{array}{l}\text { Chen et al, } \\
2016^{19}\end{array}$ & China & ABHDII-ASI & 66 & 0.578 & 0.575 & NA & 0.001 & 0.001 & 0.663 & RT-qPCR & Up-regulation \\
\hline $\begin{array}{l}\text { He et al, } \\
2016^{20}\end{array}$ & China & BANCR & 54 & 0.230 & 0.09 & 0.065 & 0.194 & 0.004 & 0.559 & RT-qPCR & Downregulation \\
\hline $\begin{array}{l}\text { Li et al, } \\
2016^{21}\end{array}$ & China & ССАТ2 & 48 & 0.750 & $0.77 \mathrm{I}$ & 0.763 & 0.014 & 0.016 & 0.563 & RT-qPCR & Up-regulation \\
\hline $\begin{array}{l}\text { Chen et al, } \\
2016^{22}\end{array}$ & China & HIFIA-AS2 & 44 & 0.748 & 0.091 & 0.501 & 0.003 & $<0.001$ & 0.540 & RT-qPCR & Up-regulation \\
\hline $\begin{array}{l}\text { Yang et al, } \\
2017^{23}\end{array}$ & China & ASAPI-ITI & 58 & 0.790 & 1.000 & NA & NA & 0.014 & 0.160 & RT-qPCR & Up-regulation \\
\hline $\begin{array}{l}\text { Lin et al, } \\
2017^{24}\end{array}$ & China & ZEBI-ASI & 55 & 0.745 & 0.792 & 0.940 & 0.001 & 0.027 & 1.000 & RT-qPCR & Up-regulation \\
\hline $\begin{array}{l}\text { Chen et al, } \\
2017^{25}\end{array}$ & China & ROR & 36 & 0.289 & 1.000 & NA & 0.000 & 0.000 & 0.000 & RT-qPCR & Up-regulation \\
\hline
\end{tabular}

Abbreviations: IncRNA, long non-coding RNA; NA, not available.

SPE, 0.78 (95\% CI, 0.62-0.89); positive likelihood ratio (PLR), 3.366 (95\% CI, 1.58-7.15); negative likelihood ratio (NLR), 0.34 (95\% CI, 0.19-0.63); and overall diagnostic OR (DOR), 11.58 (95\% CI, 3.78-35.54). Finally, the corresponding summary receiver operator characteristic (SROC) curve with an AUC was 0.82 (95\% CI, 0.78-0.85).

Due to the significant heterogeneity between these studies observed in SEN and SPE data $\left(I^{2}=95.42 \%\right.$ and $I^{2}=93.33 \%$, respectively), we constructed a meta-regression analysis including ethnicity and detected sample types. The result displayed that the detected sample types hardly affected the diagnostic accuracy for bladder cancer. By contrast, ethnicity significantly influenced SEN ( $P=0.02)$ but did not influence SPE. These results mean that lncRNA expression in an Asian population may exhibit a higher SEN in the diagnosis of bladder cancer. Importantly, there was no significant publication bias among the included studies $(P=0.466)$.

Remarkably, UCA1 lncRNA was detected in five studies, therefore we performed a separate analysis of UCA1 for the diagnosis of bladder cancer. Our meta-analysis result showed significant heterogeneity between these studies in terms of
SEN and SPE data ( $I^{2}=36.72 \%$ and $I^{2}=88.88 \%$, respectively). For this reason, the fixed effects model was used to calculate the pooled SEN parameters of the included studies and the random effects model was used to calculate the pooled SPE parameters of the included studies. As shown in Figure 2, the pooled estimates of UCA1 in the diagnosis of bladder cancer were as follows: SEN, 0.83 (95\% CI, 0.77-0.88); SPE, 0.87 (95\% CI, 0.73-0.94); PLR, 6.14 (95\% CI, 2.77-13.62); NLR, 0.20 (95\% CI, 0.13-0.30); and DOR, 30.79 (95\% CI, 9.77-97.03). Significant heterogeneity between these studies was observed in SPE data $\left(I^{2}=88.88 \%\right)$, however, metaregression analysis could not be generated due to small size. Figure 3 shows SROC curve with an AUC of 0.88 (95\% CI, 0.85-0.91). In this meta-analysis, Deeks' funnel plot asymmetry test was used to evaluate potential publication bias and, as shown in Figure 4, no significant publication bias existed among the studies $(P=0.335)$.

\section{Prognosis}

In our analysis of prognosis, the NOS was used to assess the quality of the prognostic studies selected. The scores of 
Table 2 Summary of IncRNAs used as prognostic biomarkers of bladder cancer

\begin{tabular}{|c|c|c|c|c|c|c|c|c|c|c|c|c|}
\hline \multirow[t]{2}{*}{ Study } & \multirow[t]{2}{*}{ Region } & \multirow[t]{2}{*}{ LncRNA } & \multirow[t]{2}{*}{ Expression } & \multirow[t]{2}{*}{$\begin{array}{l}\text { Detected } \\
\text { sample }\end{array}$} & \multirow[t]{2}{*}{$\begin{array}{l}\text { Test } \\
\text { method }\end{array}$} & \multirow[t]{2}{*}{ Cut-off } & \multicolumn{2}{|c|}{$\begin{array}{l}\text { Sample } \\
\text { size }\end{array}$} & \multirow[t]{2}{*}{$\begin{array}{l}\text { Survival } \\
\text { analysis }\end{array}$} & \multirow[t]{2}{*}{$\begin{array}{l}\text { HR } \\
\text { availability }\end{array}$} & \multirow[t]{2}{*}{$\begin{array}{l}\text { Follow-up } \\
\text { month }\end{array}$} & \multirow[t]{2}{*}{ NOS } \\
\hline & & & & & & & High & Low & & & & \\
\hline $\begin{array}{l}\text { Ariel et al, } \\
2000^{31}\end{array}$ & Israel & $\mathrm{HI9}$ & Up-regulation & Tissue & RT-qPCR & NA & 16 & 14 & OS & Indirectly & 80 & 5 \\
\hline $\begin{array}{l}\text { Wang et al, } \\
2013^{13}\end{array}$ & China & $\mathrm{UBCI}$ & Up-regulation & Tissue & RT-qPCR & $\mathrm{FC}>1.5$ & 60 & 42 & $\begin{array}{l}\text { OS } \\
\text { MFS }\end{array}$ & $\begin{array}{l}\text { Indirectly } \\
\text { Indirectly }\end{array}$ & 80 & 5 \\
\hline $\begin{array}{l}\text { Li et al, } \\
2014^{32}\end{array}$ & China & GHETI & Up-regulation & Tissue & RT-qPCR & Median & 39 & 41 & OS & Indirectly & 60 & 6 \\
\hline $\begin{array}{l}\text { Zhao et al, } \\
2015^{15}\end{array}$ & China & SPRY4-ITI & Downregulation & Tissue & RT-qPCR & Mean & 38 & 30 & OS & Directly & NA & 5 \\
\hline $\begin{array}{l}\text { Martínez- } \\
\text { Fernández } \\
\text { et al, 2015 }\end{array}$ & Spain & HOTAIR & Up-regulation & Tissue & RT-qPCR & Median & 30 & 33 & $\begin{array}{l}\text { PFS } \\
\text { OS }\end{array}$ & $\begin{array}{l}\text { Indirectly } \\
\text { Indirectly }\end{array}$ & $\begin{array}{l}36 \\
72\end{array}$ & 5 \\
\hline $\begin{array}{l}\text { Chen et al, } \\
2015^{34}\end{array}$ & China & n336928 & Up-regulation & Tissue & RT-qPCR & $\mathrm{FC}>2$ & 44 & 51 & OS & Directly & 60 & 5 \\
\hline $\begin{array}{l}\text { Heubach } \\
\text { et al, } 2015^{35}\end{array}$ & Germany & HOTAIR & Up-regulation & Tissue & RT-qPCR & $\mathrm{FC}>2$ & 27 & 81 & DSS & Directly & 200 & 6 \\
\hline $\begin{array}{l}\text { Duan et al, } \\
2016^{28}\end{array}$ & China & MEG3 & Downregulation & Serum & RT-qPCR & NA & 26 & 33 & RFS & Indirectly & 57 & 7 \\
\hline $\begin{array}{l}\text { Zhang et al, } \\
2016^{36}\end{array}$ & China & UNMIBC & Up-regulation & Tissue & RT-qPCR & $\mathrm{FC}>1.5$ & 42 & 33 & RFS & Directly & 36 & 6 \\
\hline $\begin{array}{l}\text { Zhang et al, } \\
2016^{37}\end{array}$ & China & GAS5 & Downregulation & Tissue & RT-qPCR & Median & 41 & 41 & DFS & Directly & 60 & 7 \\
\hline $\begin{array}{l}\text { Shang et al, } \\
2016^{38}\end{array}$ & China & HOTAIR & Up-regulation & Tissue & RT-qPCR & NA & 16 & 19 & OS & Indirectly & 40 & 5 \\
\hline $\begin{array}{l}\text { lliev et al, } \\
2016^{39}\end{array}$ & $\begin{array}{l}\text { Czech } \\
\text { Republic }\end{array}$ & TUGI & Up-regulation & Tissue & RT-qPCR & NA & 26 & 21 & OS & Directly & 100 & \\
\hline $\begin{array}{l}\text { Yan et al, } \\
2017^{23}\end{array}$ & China & ASAPI-ITI & Up-regulation & Tissue & RT-qPCR & Median & 19 & 19 & OS & Directly & 44 & 6 \\
\hline Droop & Germany & MALATI & Downregulation & Tissue & RT-qPCR & Median & 53 & 53 & OS & Directly & 200 & 6 \\
\hline et al, $2017^{40}$ & & TUGI & Downregulation & & & & & & DSS & Directly & 200 & \\
\hline & & UCAI & Downregulation & & & & & & & & & \\
\hline & & $\mathrm{UBCI}$ & Downregulation & & & & & & & & & \\
\hline & & NcRAN & Downregulation & & & & & & & & & \\
\hline & & GAS5 & Downregulation & & & & & & & & & \\
\hline & & $\mathrm{HI9}$ & Downregulation & & & & & & & & & \\
\hline $\begin{array}{l}\text { Wang et al, } \\
2017^{41}\end{array}$ & China & HULC & Up-regulation & Tissue & RT-qPCR & Median & 138 & 138 & RFS & Indirectly & 14 & 5 \\
\hline $\begin{array}{l}\text { Zhuang } \\
\text { et al, 2017 }\end{array}$ & China & LET & Downregulation & Tissue & RT-qPCR & Median & 30 & 30 & OS & Indirectly & 48 & 6 \\
\hline
\end{tabular}

Abbreviations: DFS, disease-free survival; DSS, disease-specific survival; FC, fold change; IncRNA, long non-coding RNA; MFS, metastasis-free survival; NOS, Newcastle-Ottawa Scale; OS, overall survival; PFS, progression-free survival; RFS, recurrence-free survival.

all included studies were $>5$ and regarded as high quality. The basic information from the 16 studies is summarized in Table 3. Within this analysis 16 lncRNAs were included. Among them, HOTAIR was detected in three studies, UBC1, TUG1, H19, and GAS5 were detected in two studies, and the rest were investigated in a single study. Interestingly, Droop et $\mathrm{al}^{40}$ found that decreased expression of TUG1 was associated with poor prognosis, but a study by Iliev et $\mathrm{al}^{39}$ reported that overexpression of TUG1 predicts poor prognosis. A similar contradiction was also observed regarding UBC1. Due to these contradictory reports, it was important to do a meta-analysis on the relationship between five lncRNAs' expression and the outcome of patients with bladder cancer. All results are displayed in Table 4.

Aberrant expression of all five lncRNAs required more evidence to make a definitive conclusion on OS, especially regarding TUG1 and UBC1. In addition, we found that HOTAIR was up-regulated in bladder cancer and the overexpression of HOTAIR was associated with poor disease-free survival/recurrence-free survival/disease-specific survival (DFS/RFS/DSS) (pooled HR =1.18, 95\% CI, 2.17-3.76, $P=0.006)$. Similarly, GAS5 was found to be downregulated in bladder cancer and such suppression of GAS5 was associated with a poor DFS/progression-free survival (PFS)/DSS 


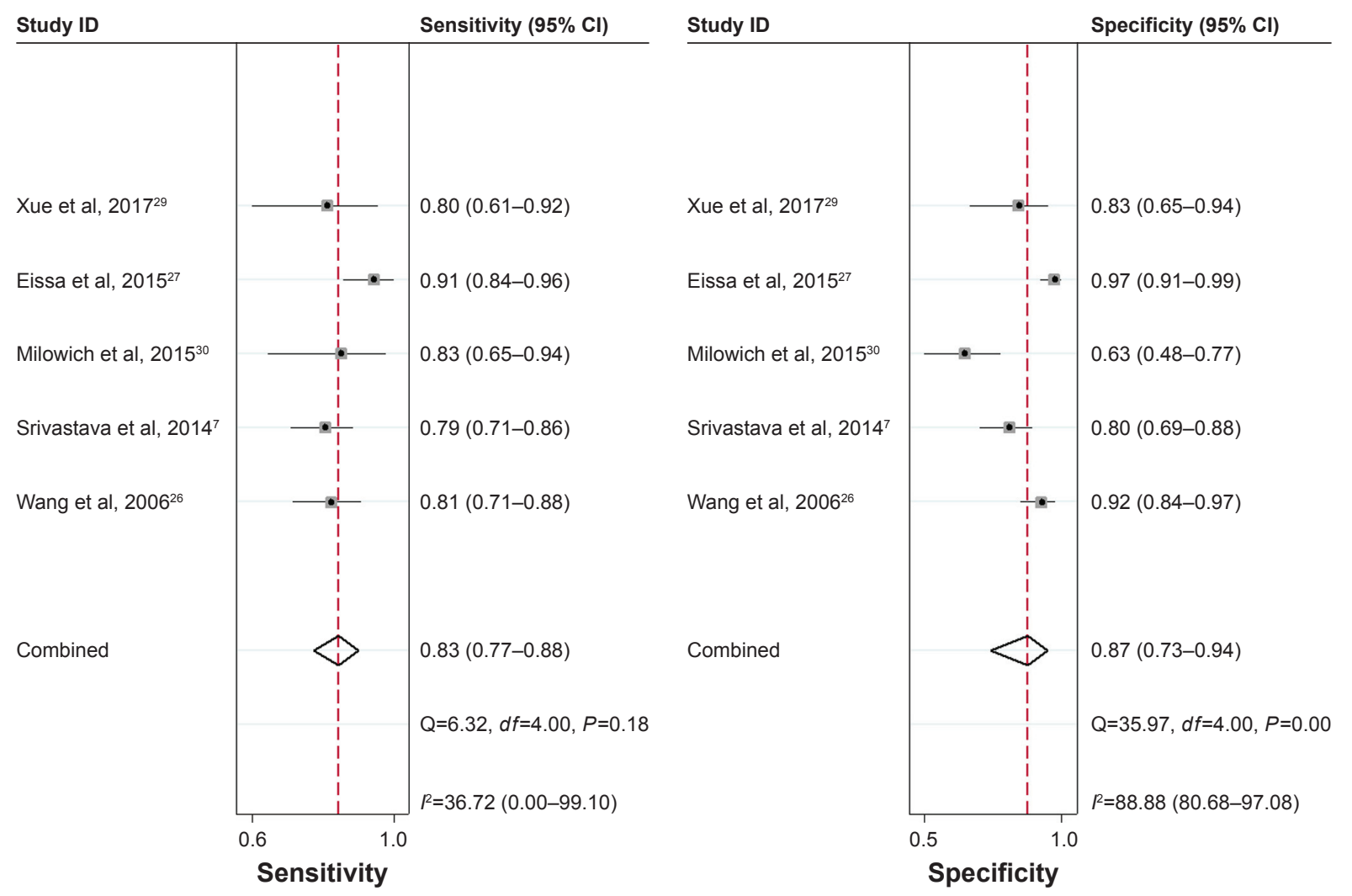

Figure 2 Forest plot of sensitivity and specificity of IncRNAs for the diagnosis of bladder cancer.

Abbreviation: IncRNA, long non-coding RNA.

(pooled HR $=0.58,95 \% \mathrm{CI}, 0.41-0.84, P=0.003$ ). However, the relationship between $\mathrm{H} 19$ and DFS/PFS/DSS remained tenuous and requires further investigation. Again, due to small sample size, we were not able to perform an SEN analysis of publication bias.

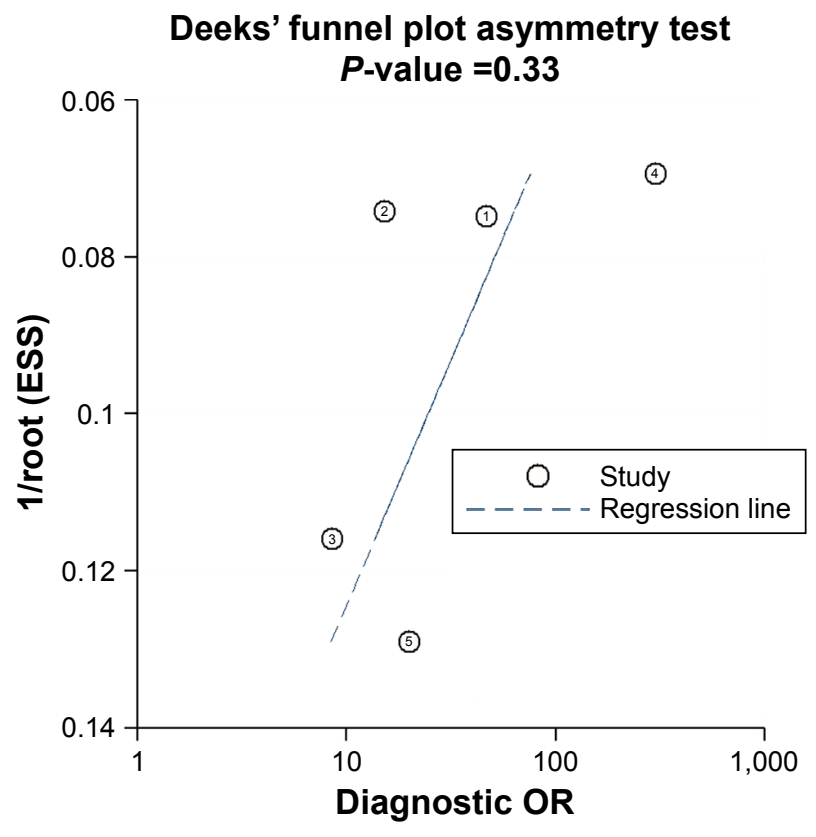

Figure 3 Deeks' funnel plot asymmetry test for publication.

\section{Discussion}

With deepening research, more and more evidence has proved that IncRNAs are closely associated with the initiation and development of cancers. Aberrant expression of lncRNAs affect many cellular processes, including proliferation,

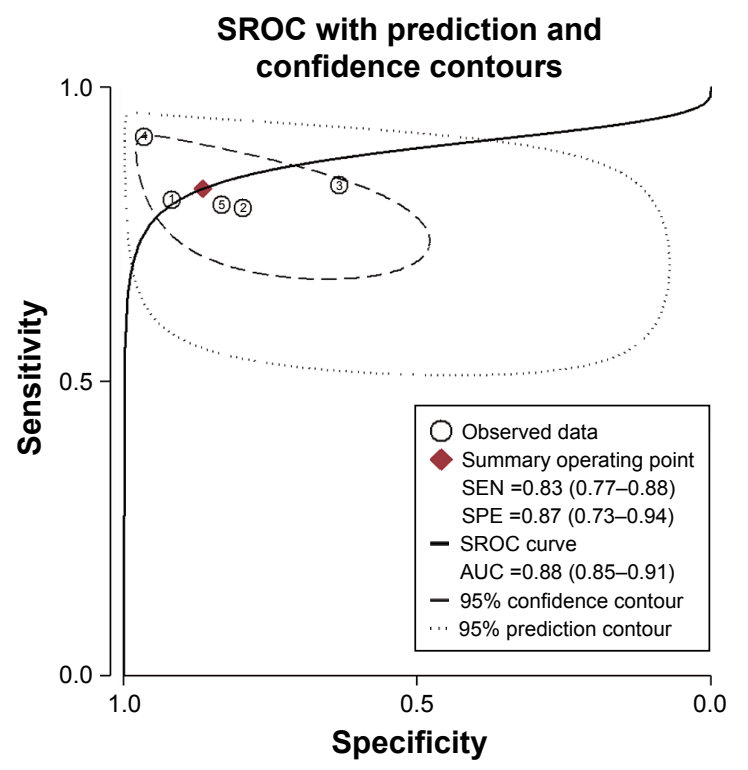

Figure 4 The summary receiver operator characteristic (SROC) curve based on UCAI. Abbreviations: SEN, sensitivity; SPE, specificity; SROC, summary receiver operator characteristic. 
Table 3 Summary of IncRNAs used as diagnostic biomarkers of bladder cancer

\begin{tabular}{|c|c|c|c|c|c|c|c|c|c|c|}
\hline \multirow[t]{2}{*}{ Study } & \multirow[t]{2}{*}{ Region } & \multirow[t]{2}{*}{ LncRNA } & \multirow[t]{2}{*}{ Expression } & \multirow[t]{2}{*}{ SEN (\%) } & \multirow[t]{2}{*}{ SPE (\%) } & \multirow[t]{2}{*}{ AUC } & \multicolumn{2}{|c|}{ Sample size } & \multirow{2}{*}{$\begin{array}{l}\text { Detected } \\
\text { sample }\end{array}$} & \multirow[t]{2}{*}{ QUADAS-2 } \\
\hline & & & & & & & Case & Control & & \\
\hline $\begin{array}{l}\text { Wang et al, } \\
2006^{26}\end{array}$ & China & UCAI & Up-regulation & 91.60 & 81.30 & 0.882 & 94 & 85 & Urine & 6 \\
\hline $\begin{array}{l}\text { Srivastava } \\
\text { et al, 2014 }\end{array}$ & India & UCAI & Up-regulation & 79.49 & 79.73 & 0.863 & 117 & 74 & Urine & 5 \\
\hline $\begin{array}{l}\text { Milowich et al, } \\
2015^{30}\end{array}$ & Belgium & UCAI & Up-regulation & 70 & 70.7 & NA & 69 & 93 & Urine & 5 \\
\hline $\begin{array}{l}\text { Eissa et al, } \\
2015^{27}\end{array}$ & Egypt & UCAI & Up-regulation & 91.50 & 96.50 & 0.975 & 94 & 116 & Urine & 6 \\
\hline $\begin{array}{l}\text { Duan et al, } \\
2016^{28}\end{array}$ & China & MEG3 & Downregulation & 70.00 & 75.80 & 0.798 & 120 & 52 & Serum & 6 \\
\hline $\begin{array}{l}\text { Duan et al, } \\
2016^{28}\end{array}$ & China & SNHGI6 & Up-regulation & 64.20 & 65.00 & 0.687 & 120 & 52 & Serum & 5 \\
\hline $\begin{array}{l}\text { Duan et al, } \\
2016^{28}\end{array}$ & China & MALATI & Up-regulation & 56.70 & 67.50 & 0.640 & 120 & 52 & Serum & 5 \\
\hline $\begin{array}{l}\text { Xue et al, } \\
2017^{29}\end{array}$ & China & UCAI & Up-regulation & 80.00 & 83.33 & 0.878 & 30 & 30 & Serum & 5 \\
\hline
\end{tabular}

Abbreviations: IncRNAs, long non-coding RNAs; QUADAS-2, Quality Assessment of Diagnostic Accuracy Studies-2; SEN, sensitivity; SPE, specificity.

migration, invasion, and apoptosis. Further clinical findings demonstrated that aberrant expression of lncRNAs was related to the clinical outcomes of cancer patients. As one of the most common malignant tumors, the outcomes for bladder cancer are quite poor, with a $50 \%$ recurrence rate and $15 \%-40 \%$ developing into muscle-invasive disease. ${ }^{43}$ This meta-analysis was designed to identify possible biomarkers for bladder cancer.

To analyze the relationship between lncRNA expression and clinical features of bladder cancer, 13 studies were included in our comprehensive systematic review. In this study, we found that no lncRNAs were significantly associated with gender, age, and tumor size. Additionally, almost all aberrant lncRNAs were associated with histological grade, including SPRY4-IT1, PANDAR, ZEB1-AS1, ROR, SUMO1P3, ABHD11-AS1, AATBC, CCAT2, and HIF1A-AS2. Nearly all studies demonstrated that lncRNAs were significantly correlated with tumor stage. Finally, our results showed a correlation between the up-regulation of lncRNA SPRY4-IT1, UBC1, and ROR and lymph node metastasis, which was significant. This finding might suggest that lncRNAs may be biomarkers for lymph node metastasis. However, this conclusion should be further verified due to limitation within the included studies.

There is a lack of a satisfactory method to diagnose bladder cancer. Until now, cystoscopy screening, random

Table 4 The relationship between five IncRNAs and the survival of patients with bladder cancer

\begin{tabular}{|c|c|c|c|c|c|c|c|c|}
\hline \multirow[t]{2}{*}{ IncRNA } & \multirow{2}{*}{$\begin{array}{l}\text { Number } \\
\text { of studies }\end{array}$} & \multicolumn{4}{|c|}{ Test of association } & \multicolumn{3}{|c|}{ Test of heterogeneity } \\
\hline & & $\begin{array}{l}\text { Pooled HR } \\
(95 \% \mathrm{Cl})\end{array}$ & $\mathbf{Z}$ & $P$-value & Model & $\begin{array}{l}\text { chi-squared } \\
\text { test }\end{array}$ & $P$-value & $I^{2}(\%)$ \\
\hline \multicolumn{9}{|l|}{ HOTAIR } \\
\hline OS & I & $1.18(0.21-6.77)$ & - & - & - & - & - & - \\
\hline RFS/DFS/DSS & 2 & $2.17(1.25-3.76)$ & 2.75 & 0.006 & $\mathrm{R}$ & 0.03 & 0.868 & 0.00 \\
\hline \multicolumn{9}{|l|}{ TUGI } \\
\hline OS & 2 & $1.16(0.27-4.94)$ & 0.21 & 0.838 & $\mathrm{~F}$ & 9.89 & 0.002 & 89.90 \\
\hline RFS/DFS/DSS & 1 & $0.59(0.36-0.97)$ & - & - & - & - & - & - \\
\hline \multicolumn{9}{|l|}{ UBCI } \\
\hline OS & 2 & $0.96(0.64-1.46)$ & 0.17 & 0.862 & $\mathrm{R}$ & 0.03 & 0.855 & 0.00 \\
\hline RFS/DFS/DSS & 1 & $0.97(0.59-1,59)$ & - & - & - & - & - & - \\
\hline \multicolumn{9}{|l|}{ GAS5 } \\
\hline OS & 1 & $0.71(0.46-1.09)$ & - & - & - & - & - & - \\
\hline RFS/DFS/DSS & 2 & $0.58(0.4 \mathrm{I}-0.84)$ & 2.92 & 0.003 & $\mathrm{R}$ & 0.99 & 0.349 & 0.00 \\
\hline \multicolumn{9}{|l|}{$\mathrm{HIO}$} \\
\hline OS & I & $0.90(0.59-1.39)$ & - & - & - & - & - & - \\
\hline RFS/DFS/DSS & 2 & $0.93(0.58-1.49)$ & 0.30 & 0.762 & $\mathrm{R}$ & 0.00 & 0.953 & 0.00 \\
\hline
\end{tabular}

Abbreviations: DFS, disease-free survival; DSS, disease-specific survival; IncRNA, long non-coding RNA; OS, overall survival; RFS, recurrence-free survival; R, random-effects model; $F$, fixed-effects model. 
bladder biopsies, and voided urinary cytology remain the most commonly used methods for the initial diagnosis of bladder cancer. However, the former two methods are invasive and uncomfortable, and the latter method has a low SEN for the detection of bladder cancer. ${ }^{44,45}$ For these reasons, identification of a highly sensitive, highly specific, and non-invasive method to detect bladder cancer is necessary. In this meta-analysis, we found that lncRNAs are expected to be diagnostic biomarkers for bladder cancer, especially UCA1.

A meta-analysis was executed to assess the diagnostic ability of UCA1. The results of pooled estimates of UCA1 in the diagnosis of bladder cancer were as follows: SEN, 0.83 (95\% CI, 0.77-0.88), SPE, 0.87 (95\% CI, 0.73-0.94), and SROC curve with an AUC of 0.88 (95\% CI, 0.85-0.91). This result suggested that UCA1 was a satisfactory diagnostic biomarker for bladder cancer. Compared with single lncRNA, a combination of several lncRNAs might be more suitable to diagnose bladder cancer. Duan et al found that the diagnostic performance of the lncRNA panel (MEG3, SNHG16, and MALAT1) for Ta, T1, and T2-T4 was significantly higher than that of urine cytology respectively. ${ }^{28}$ Bao et al also found that a four-lncRNA panel could be a novel independent biomarker for predicting survival in patients with bladder cancer, independent of other clinical variables. Further results showed that these four prognostic lncRNAs may be involved in known bladder cancer-related biological processes and pathways. ${ }^{46}$

Regarding prognostic value, the present study contained analysis of 16 aberrant lncRNAs, including six up-regulated lncRNAs, seven downregulated lncRNAs, and three controversial lncRNAs. However, only five lncRNAs were repeatedly reported. Additionally, we conducted a meta-analysis to analyze the association between lncRNA expression and the prognosis of patients with bladder cancer. As a result, it was observed that HOTAIR was up-regulated in bladder cancer and the overexpression of HOTAIR was associated with poor DFS/RFS/DSS, while GAS5 was downregulated in bladder cancer and the suppressed expression of GAS5 was associated with poor DFS/PFS/DSS. This result is similar in other tumors. Shen et al found that overexpression of HOTAIR was associated with lower OS/DFS and high levels of GAS5 were associated with better OS/DFS in patients with glioblastoma. ${ }^{47} \mathrm{Cui}$ et al also displayed that HOTAIR and GAS5 levels in tissues could act as predictors of survival in patients with cervical cancer, by meta-analysis. ${ }^{48}$ However, the result showed that there was no statistical significance between three controversial lncRNAs' expression
(TUG1, UBC1, and H19) and the prognosis of patients with bladder cancer. Therefore, to verify the relationship, more evidence is needed.

Several limitations to this study should be considered. Firstly, the number of studies included in the meta-analysis was less than desirable. Data on individual lncRNAs appeared only once among the incorporated studies and few lncRNAs appeared in more than two different studies; a fact which would influence the sample heterogeneity. Secondly, different sample types (tissue, serum, and urine) and different follow-up times used in the studies induced heterogeneity. Certainly, the cut-off value and method of determining low or high levels of IncRNAs varied between different studies; and although RT-qPCR was used as the standard method to evaluate the expression of lncRNAs, this also might have caused heterogeneity of the results. To improve comparability among studies, researchers should develop a cut-off value with enhanced consistency and establish a standard method to classify high or low lncRNA expression. Thirdly, we extracted HR and 95\% CI values from Kaplan-Meier curve according to Tierney's methodology, due to lack of survival data, which may have caused potential heterogeneity. ${ }^{49}$ Fourthly, because most of the selected literature came from China, the conclusions drawn from the subgroup analysis on ethnicity need further verification. As for publication bias, language bias existed because only English publications were included in this study and no studies with negative results were published, perhaps leading to overestimated pooled effect value.

\section{Conclusion}

Taken together, the present study is the first meta-analysis to assess the expression of lncRNAs and their clinical value in patients with bladder cancer. As a result, several specific lncRNAs were identified to be significantly associated with the prognosis of patients with bladder cancer, and could potentially be used as predictive biomarkers for patient survival. Among them, UCA1 was expected to be a diagnostic biomarker for bladder cancer, while the aberrant expression of HOTAIR and GAS5 was associated with poor DFS/RFS/DSS. However, further large-scale studies should be carried out to confirm our findings and to verify the clinical value of lncRNAs in bladder cancer.

\section{Acknowledgments}

This study was supported by grants from the National Natural Science Foundation of China (no 81101922), Science and Technology Development Fund Project of Shenzhen 
(noJCYJ20150403091443329and JCYJ20170307111334308), the fund of "San-ming" Project of Medicine in Shenzhen (no SZSM201612066), and the fund of Guangdong Key Medical Subject.

\section{Author contributions}

JQ and XP contributed to data collection, data analysis, and manuscript writing. LWZ and ZWL contributed to data collection and data analysis. KFD, FLY, SYL, and HFM contributed to data analysis. YQL designed this study. All authors contributed toward data analysis, drafting and critically revising the paper and agree to be accountable for all aspects of the work.

\section{Disclosure}

The authors report no conflicts of interest in this work.

\section{References}

1. Babjuk M, Böhle A, Burger M, et al. EAU Guidelines on Non-Muscleinvasive Urothelial Carcinoma of the Bladder: Update 2016. Eur Urol. 2017;71(3):447-461

2. Kubota Y, Nakaigawa N. Committee for Establishment of the Clinical Practice Guideline for the Management of Bladder Cancer and the Japanese Urological Association. Essential content of evidence-based clinical practice guidelines for bladder cancer: The Japanese Urological Association 2015 update. Int J Urol. 2016;23(8):640-645.

3. Clark PE, Spiess PE, Agarwal N, et al. NCCN Guidelines Insights: Bladder Cancer, Version 2.2016. J Natl Compr Canc Netw. 2016; 14(10):1213-1224.

4. Gutschner T, Diederichs S. The hallmarks of cancer: a long non-coding RNA point of view. RNA Biol. 2012;9(6):703-719.

5. Wapinski O, Chang HY. Long noncoding RNAs and human disease. Trends Cell Biol. 2011;21(6):354-361.

6. Jiang C, Yang Y, Yang Y, et al. LncRNA-HOTAIR affects tumorigenesis and metastasis of non-small cell lung cancer by up-regulating miR-613. Oncol Res. 2018;26(5):725-734.

7. Srivastava AK, Singh PK, Rath SK, et al. Appraisal of diagnostic ability of UCA1 as a biomarker of carcinoma of the urinary bladder. Tumour Biol. 2014;35(11):11435-11442.

8. Lee GL, Dobi A, Srivastava S. Prostate cancer: diagnostic performance of the PCA3 urine test. Nat Rev Urol. 2011;8(3):123-124.

9. Walsh AL, Tuzova AV, Bolton EM, Lynch TH, Perry AS. Long noncoding RNAs and prostate carcinogenesis: the missing 'linc'? Trends Mol Med. 2014;20(8):428-436.

10. Whiting PF, Rutjes AW, Westwood ME, et al. QUADAS-2: a revised tool for the quality assessment of diagnostic accuracy studies. Ann Intern Med. 2011;155(8):529-536.

11. Lo CK, Mertz D, Loeb M. Newcastle-Ottawa Scale: comparing reviewers' to authors' assessments. BMC Med Res Methodol. 2014;14:45.

12. Gu L, Li H, Chen L, et al. MicroRNAs as prognostic molecular signatures in renal cell carcinoma: a systematic review and meta-analysis. Oncotarget. 2015;6(32):32545-32560.

13. Wang H, Cai Q, Sun F, et al. linc-UBC1 physically associates with polycomb repressive complex 2 (PRC2) and acts as a negative prognostic factor for lymph node metastasis and survival in bladder cancer. Biochim Biophys Acta. 2013;1832(10):1528-1537.

14. Zhao F, Lin T, He W, et al. Knockdown of a novel lincRNA AATBC suppresses proliferation and induces apoptosis in bladder cancer. Oncotarget. 2015;6(2):1064-1078.

15. Zhao XL, Zhao ZH, Xu WC, Hou JQ, du XY. Increased expression of SPRY4-IT1 predicts poor prognosis and promotes tumor growth and metastasis in bladder cancer. Int J Clin Exp Pathol. 2015;8(2):1954-1960.
16. Zhan Y, Lin J, Liu Y, et al. Up-regulation of long non-coding RNA PANDAR is associated with poor prognosis and promotes tumorigenesis in bladder cancer. J Exp Clin Cancer Res. 2016;35(1):83.

17. He A, Chen Z, Mei H, Liu Y. Decreased expression of LncRNA MIR31HG in human bladder cancer. Cancer Biomark. 2016;17(2): 231-236.

18. Zhan Y, Liu Y, Wang C, et al. Increased expression of SUMO1P3 predicts poor prognosis and promotes tumor growth and metastasis in bladder cancer. Oncotarget. 2016;7(13):16038-16048.

19. Chen M, Li J, Zhuang C, Cai Z. Increased lncRNA ABHD11-AS1 represses the malignant phenotypes of bladder cancer. Oncotarget. 2017;8(17):28176-28186.

20. He A, Liu Y, Chen Z, et al. Over-expression of long noncoding RNA BANCR inhibits malignant phenotypes of human bladder cancer. $J$ Exp Clin Cancer Res. 2016;35(1):125.

21. Li J, Zhuang C, Liu Y, et al. shRNA targeting long non-coding RNA CCAT2 controlled by tetracycline-inducible system inhibits progression of bladder cancer cells. Oncotarget. 2016;7(20):28989-28997.

22. Chen M, Zhuang C, Liu Y, et al. Tetracycline-inducible shRNA targeting antisense long non-coding RNA HIF1A-AS2 represses the malignant phenotypes of bladder cancer. Cancer Lett. 2016;376(1): 155-164.

23. Yang L, Xue Y, Liu J, et al. Long noncoding RNA ASAP1-IT1 promotes cancer stemness and predicts a poor prognosis in patients with bladder cancer. Neoplasma. 2017;64(6):847-855.

24. Lin J, Zhan Y, Liu Y, et al. Increased expression of ZEB1-AS1 correlates with higher histopathological grade and promotes tumorigenesis in bladder cancer. Oncotarget. 2017;8(15):24202-24212.

25. Chen Y, Peng Y, Xu Z, et al. LncROR Promotes Bladder Cancer Cell Proliferation, Migration, and Epithelial-Mesenchymal Transition. Cell Physiol Biochem. 2017;41(6):2399-2410.

26. Wang XS, Zhang Z, Wang HC, et al. Rapid identification of UCA1 as a very sensitive and specific unique marker for human bladder carcinoma. Clin Cancer Res. 2006;12(16):4851-4858.

27. Eissa S, Matboli M, Essawy NO, Kotb YM. Integrative functional genetic-epigenetic approach for selecting genes as urine biomarkers for bladder cancer diagnosis. Tumour Biol. 2015;36(12):9545-9552.

28. Duan W, du L, Jiang X, et al. Identification of a serum circulating IncRNA panel for the diagnosis and recurrence prediction of bladder cancer. Oncotarget. 2016;7(48):78850-78858.

29. Xue M, Chen W, Xiang A, et al. Hypoxic exosomes facilitate bladder tumor growth and development through transferring long non-coding RNA-UCA1. Mol Cancer. 2017;16(1):143.

30. Milowich D, Le Mercier M, de Neve N, et al. Diagnostic value of the UCA1 test for bladder cancer detection: a clinical study. Springerplus. 2015;4:349.

31. Ariel I, Sughayer M, Fellig Y, et al. The imprinted H19 gene is a marker of early recurrence in human bladder carcinoma. Mol Pathol. 2000;53(6):320-323.

32. Li LJ, Zhu JL, Bao WS, et al. Long noncoding RNA GHET1 promotes the development of bladder cancer. Int J Clin Exp Pathol. 2014;7(10): 7196-7205.

33. Martínez-Fernández M, Feber A, Dueñas M, et al. Analysis of the Polycomb-related lncRNAs HOTAIR and ANRIL in bladder cancer. Clin Epigenetics. 2015;7:109.

34. Chen T, Xie W, Xie L, et al. Expression of long noncoding RNA lncRNA-n336928 is correlated with tumor stage and grade and overall survival in bladder cancer. Biochem Biophys Res Commun. 2015;468(4): 666-670.

35. Heubach J, Monsior J, Deenen R, et al. The long noncoding RNA HOTAIR has tissue and cell type-dependent effects on HOX gene expression and phenotype of urothelial cancer cells. Mol Cancer. 2015; 14:108.

36. Zhang S, Zhong G, He W, et al. IncRNA Up-Regulated in Nonmuscle Invasive Bladder Cancer Facilitates Tumor Growth and Acts as a Negative Prognostic Factor of Recurrence. J Urol. 2016;196(4):1270-1278. 
37. Zhang H, Guo Y, Song Y, Shang C. Long noncoding RNA GAS5 inhibits malignant proliferation and chemotherapy resistance to doxorubicin in bladder transitional cell carcinoma. Cancer Chemother Pharmacol. 2017;79(1):49-55.

38. Shang C, Guo Y, Zhang H, Xue YX. Long noncoding RNA HOTAIR is a prognostic biomarker and inhibits chemosensitivity to doxorubicin in bladder transitional cell carcinoma. Cancer Chemother Pharmacol. 2016;77(3):507-513.

39. Iliev R, Kleinova R, Juracek J, et al. Overexpression of long non-coding RNA TUG1 predicts poor prognosis and promotes cancer cell proliferation and migration in high-grade muscle-invasive bladder cancer. Tumour Biol. 2016;37(10):13385-13390.

40. Droop J, Szarvas T, Schulz WA, et al. Diagnostic and prognostic value of long noncoding RNAs as biomarkers in urothelial carcinoma. PLoS One. 2017;12(4):e0176287.

41. Wang J, Ma W, Liu Y. Long non-coding RNA HULC promotes bladder cancer cells proliferation but inhibits apoptosis via regulation of ZIC2 and PI3K/AKT signaling pathway. Cancer Biomark. 2017;20(4): 425-434.

42. Zhuang J, Shen L, Yang L, et al. TGF $\beta 1$ Promotes Gemcitabine Resistance through Regulating the LncRNA-LET/NF90/miR-145 Signaling Axis in Bladder Cancer. Theranostics. 2017;7(12):3053-3067.
43. Amin MB, Smith SC, Reuter VE, et al. Update for the practicing pathologist: The International Consultation On Urologic DiseaseEuropean association of urology consultation on bladder cancer. Mod Pathol. 2015;28(5):612-630.

44. Kamat AM, Hahn NM, Efstathiou JA, et al. Bladder cancer. Lancet. 2016;388(10061):2796-2810.

45. Olivieri M, Ferro M, Terreri S, et al. Long non-coding RNA containing ultraconserved genomic region 8 promotes bladder cancer tumorigenesis. Oncotarget. 2016;7(15):20636-20654.

46. Bao Z, Zhang W, Dong D. A potential prognostic lncRNA signature for predicting survival in patients with bladder urothelial carcinoma. Oncotarget. 2017;8(6):10485-10497.

47. Shen J, Hodges TR, Song R, et al. Serum HOTAIR and GAS5 levels as predictors of survival in patients with glioblastoma. Mol Carcinog. 2018;57(1):137-141.

48. Cui $\mathrm{X}$, Jing $\mathrm{X}, \mathrm{Wu} \mathrm{X}$. The prognostic value of long non coding RNAs in cervical cancer: A meta-analysis. Oncotarget. 2017;8(37): 62470-62477.

49. Tierney JF, Stewart LA, Ghersi D, Burdett S, Sydes MR. Practical methods for incorporating summary time-to-event data into meta-analysis. Trials. 2007;8:16.
OncoTargets and Therapy

\section{Publish your work in this journal}

OncoTargets and Therapy is an international, peer-reviewed, open access journal focusing on the pathological basis of all cancers, potential targets for therapy and treatment protocols employed to improve the management of cancer patients. The journal also focuses on the impact of management programs and new therapeutic agents and protocols on

\section{Dovepress}

patient perspectives such as quality of life, adherence and satisfaction The manuscript management system is completely online and includes a very quick and fair peer-review system, which is all easy to use. Visit http://www.dovepress.com/testimonials.php to read real quotes from published authors. 